\title{
Ours is a Broad Church: Indirectly Evaluative Legal Philosophy as a Facet of Jurisprudential Inquiry
}

\author{
Julie Dickson*
}

\begin{abstract}
:
Questions concerning the aims and aspirations, criteria of success and even proper delineation of the subject matter of theories of law, have given rise to some of the most intractable and contentious debates in contemporary legal philosophy. In this article, I outline my vision of the remit and character of legal philosophy, with particular emphasis on the methodological approach with which I am most concerned in my own work, and which I refer to here as 'indirectly evaluative legal philosophy' (IELP). I do so partly in response to some vehement criticisms of, and, in my view, significant mischaracterisations of, IELP and cognate approaches to theorising about law, which feature in some recent jurisprudential debates. My position, which I am in the process of developing in depth in a new monograph, supports a pluralistic methodological outlook which emphasises disciplinary and sub-disciplinary complementarity as an alternative to the febrile adversarialism sometimes afflicting our discipline. For, in my view, ours is a broad church, and all theoretical accounts able to illuminate and help us understand any aspect of law's variegated and complex character are (to invoke a Scottish saying) welcome in the main body o' the kirk.
\end{abstract}

Keywords: JURISPRUDENCE; LEGAL PHILOSOPHY; METHODOLOGY; INDIRECTLY EVALUATIVE LEGAL PHILOSOPHY; METHODOLOGICAL PLURALISM

\section{INTRODUCTION}

Questions concerning the aims and aspirations, criteria of success and even proper delineation of the subject matter of theories of law, have given rise to some of the most intractable and contentious debates in contemporary legal philosophy. In broad terms, these

\footnotetext{
"Fellow and Senior Law Tutor, Somerville College, Oxford; Associate Professor, Faculty of Law, University of Oxford. Email: julie.dickson@law.ox.ac.uk This article is dedicated to my late uncle, lan Maxwell, whose encouragement early on in my life meant so much to me. Thanks are due to Richard Broadhead, Roger Cotterrell, Timothy Endicott, John Gardner, Michael Giudice, Joseph Raz, Juan Vega Gómez and Wil Waluchow, all of whom have productively influenced my thinking on the issues discussed here. I am also grateful to Sean Coyle and George Pavlakos in their capacity as editors, and to two anonymous peer reviewers for this journal, whose thought-provoking comments have improved this article, and will assist me greatly in future work on this topic.
} 
debates might be categorised as concerning a distinctive sub-topic within legal philosophy, namely the methodology of legal philosophy. And indeed, in the recent history of the discipline, such inquiries, and the questions they address, have frequently been termed, including by many of those engaging in them, as 'methodological' in character. ${ }^{1}$ This, however, may be a problematically limiting term, connoting an overly restrictive view of the ambit of such inquiries. Referring to the 'methodology' of legal philosophy may give the misleading impression that the relevant inquiries concern only the way in which legal philosophy is done, rather than encompassing, in a very broad sense, inquiry into what legal philosophy is: its aims, criteria of success, evidence base, constraints and prospects for progress, and indeed how we should determine and understand its very domain and subject matter. Understood in this broader sense, the relevant area of inquiry addresses (but is not limited to) the following questions: what are and ought to be the aims and aspirations of legal philosophy?; how should legal theorists approach and engage in their task, and what constraints are incumbent on them as they do so?; what are legal philosophy's proper methods, tools and limits?; which questions does and should it seek to address?; what counts as a legal philosophical or jurisprudential question and how should we delineate the discipline's domain of inquiry?; what relations hold between legal philosophy and neighbouring disciplines and sub-disciplines, such as social, moral and political philosophy, and empirical, sociological and doctrinal accounts of law?; in virtue of what, if anything, might legal philosophical claims be true or false?; what are the criteria of success of philosophy of law, and how do we know if they have been met?; can there be progress in legal philosophy?

It is this broad assemblage of questions which have fascinated and challenged me in much of my own academic work. And although I, too, have previously referred to such inquiries as concerning the 'methodology' of legal philosophy, ${ }^{2}$ in light of the point above regarding the more restrictive ambit which this term may connote, I now think it better where possible - to refer to this topic, and its many puzzles and disputes, as 'the philosophy of legal philosophy.'

This article presents in outline my views on some of the questions mentioned above. My aim is to convey the spirit of my stance on the character and tasks of various facets of legal philosophy; in particular, the facet of such inquiry to which I am drawn in my own

\footnotetext{
${ }^{1}$ eg Stephen Perry, 'Hart's Methodological Positivism' in (1998) 4 Legal Theory 427; Brian Leiter, 'Beyond the Hart/Dworkin Debate: The Methodology Problem in Jurisprudence', (2003) 48 American Journal of Jurisprudence 17; Andrew Halpin, 'The Methodology of Jurisprudence: Thirty Years Off the Point' (2006) 19 Canadian Journal of Law and Jurisprudence 67.

2 eg Julie Dickson, 'Methodology in Jurisprudence: a critical survey’ (2004) 10 Legal Theory 117.

${ }^{3}$ I am currently writing a monograph on this topic, working title: Elucidating Law: The Philosophy of Legal Philosophy, which is under contract with Oxford University Press. nb I say 'where possible' above to take account of the fact that, as will be clear from the following discussion, it is likely impossible entirely to avoid use of the terms 'methodology', 'methodological' etc in this area, owing to their established prevalence in the literature and debates to date.
} 
work, and which is referred to here as 'indirectly evaluative legal philosophy' (IELP). ${ }^{4}$ The discussion proceeds in part via identifying, and responding to, some vehement criticisms of, and, in my view, significant mis-characterisations of, indirectly evaluative legal philosophy and cognate approaches to theorising about law in recent jurisprudential debates. My response, however, largely takes the form not of an attempted point-by-point rebuttal of each of these criticisms and mischaracterisations, but rather of a plea for all participants in this area of inquiry to be less combative in their bearing, as current excessive disputation has led to much misdirected time and effort in the relevant debates, and to unhelpful and false oppositions within legal philosophy as a whole.

My own stance emerges from what I hope is a less disputatious and more pluralistic theoretical outlook: an outlook which, amongst other things, emphasizes - where possible - disciplinary and sub-disciplinary complementarity, rather than the febrile adversarialism sometimes afflicting our discipline. For in my view, ours is a broad church, and all theoretical accounts able to illuminate and help us understand any aspect of law's variegated and complex character are (to invoke a Scottish saying) welcome in the main body o' the kirk.

I begin, in section $2 \mathrm{~A}$ below, by considering how we should understand the aims and aspirations of legal philosophy, and argue in favour of a 'broad church' understanding of our discipline. I then move on, in section $2 \mathrm{~B}$, to discuss some vehemently negative characterisations of indirectly evaluative legal philosophy (IELP) and cognate approaches to theorising about law. After attempting to turn aside the unhelpful and misleading polarization which such views frequently instigate and sustain, section 3 of the article embarks upon a more constructive task: that of conveying the central tenets of IELP, the particular approach to legal philosophy which I champion. As the discussion proceeds, and concludes in section 4 , I hope to indicate the sense in which this facet of legal philosophy - IELP - can and should be productively combined with other facets of legal philosophical inquiry, enabling our discipline as a whole to cast multiple and complementary shafts of light over the complex array of phenomena constituting law.

\section{LEGAL PHILOSOPHY: OF ITS DEVILS AND ITS DEEDS 5}

\section{(A) Of Deeds}

In the preceding section, I talked, perhaps somewhat airily, of 'the philosophy of legal philosophy', 'the criteria of success of legal philosophy', and so on, without pausing to state precisely what I take 'legal philosophy' to be. In one sense, this lack of specification is

\footnotetext{
${ }^{4}$ Some of my earlier work featured discussion of particular aspects of this approach, see eg J Dickson, Evaluation and Legal Theory (Hart Publishing, 2001); J Dickson, 'The Central Questions of Legal Philosophy' (2003) 56 Current Legal Problems 63; Dickson (n 2). My planned monograph, Dickson (n 3), will offer wide-ranging discussions of the approach as a whole.

${ }^{5}$ With a little bit of inspiration from the wonderful, 'A Case of You', written and produced by Joni Mitchell, from the album Blue, all tracks composed, arranged and produced by Joni Mitchell, released by Warner Bros/Reprise, 1971.
} 
inevitable at the beginning of the inquiry, especially given my view that what legal philosophy is, and what are and ought to be its proper ambit, aims, and questions, constitute a fundamental part of what is to be discussed and determined in the account I seek to develop.

However, I may also be allowing myself a certain liberality of usage as regards 'legal philosophy', because, whatever answers are to be given to the questions mentioned in section 1 above, I do not set much store by certain of the distinctions some legal philosophers draw between allegedly different parts or perhaps sub-parts of our discipline. In particular, contra some other legal philosophers, I am not using 'legal philosophy' in contradistinction to 'legal theory', or to 'jurisprudence.' My stance in this regard might usefully be contrasted with that of Roger Cotterrell, who, in an illuminating and thought-provoking article recently published in this journal, draws what he regards as an important distinction between 'legal philosophy' and 'jurisprudence', and seeks to show that these enterprises ought not to be confused with one another, nor held to the same criteria of success. ${ }^{6}$

Cotterrell views 'legal philosophy' as, 'the branch of philosophy that takes law as its object', ${ }^{7}$ and as presenting itself as having, 'a clear identity ... and strong intellectual underpinnings located in philosophy. Its methods, choice of problems, forms of argument and criteria of relevance are seen as validated by philosophy as an academic discipline ...'8 Jurisprudence, on the other hand, should be understood as, 'aimed at informing those who are enduringly (usually professionally) concerned with the well-being of the idea of law as a practice ... equipping them with the means of promoting that well-being ... ', ${ }^{9}$ and as distinguishable from other inquiries into the character of law in terms of 'its potential for informing the prudentia of the jurist, centred on the craft-skills (and, one might hope, wisdom) involved in making sense of the complexity of law as ideal, practice and experience in its time and place. ${ }^{10}$

In the above passages, and indeed throughout the article, Cotterrell seems to use his legal philosophy/jurisprudence dichotomy to demarcate and contrast several different sets of qualities which he takes these enterprises respectively to exhibit. At least three purported distinctions are drawn, each of which attempts to differentiate legal philosophy

\footnotetext{
${ }^{6}$ R Cotterrell, 'Why Jurisprudence Is Not Legal Philosophy' (2014) 5 Jurisprudence 41. This rich and stimulating article provided a considerable part of the impetus for the present discussion. It should be noted, however, that I do not seek to engage directly with, nor attempt to refute, each of Cotterrell's points in his article, many of which are well-taken, and indeed in many respects are consonant with my own views on the character of our discipline. Rather, I use only certain points in his article as thought-provoking springboards from which to launch and elaborate upon aspects of my own work, and to highlight what may be areas of disagreement between us, amidst much that is shared. Sincere thanks are due to Professor Cotterrell both for sending me his article initially, and for the very helpful email exchange he kindly had with me regarding it, which served further to convince me that we share much in approach and outlook, even as we may disagree on more particular points regarding the respective character of jurisprudence and of legal philosophy.

${ }^{7}$ Cotterrell (n 6) at 41.

8 Ibid 41.

9 Ibid 42.

${ }^{10} \mathrm{lbid} 55$ (italics in original).
} 
from jurisprudence along different axes, in terms of: (i) the audience they respectively seek to address - academics with an interest in legal philosophy vs. lawyers/judges/jurists in need of the insights of jurisprudence ${ }^{11}$; (ii) the aspects of law, and the character of the problems concerning those aspects of law that they focus upon - abstract problems far removed from legal practice which are engaged with only because of their intrinsic philosophical interest (legal philosophy) vs. actual institutions and practices of law, and puzzles of juristic experience in all their practical complexity (jurisprudence) ${ }^{12}$; and (iii) their alleged disciplinary credentials and concomitant methods by which they are to be, in Cotterrell's terms 'validated' 13 - methods, problems, criteria of success being 'validated' by their relation to the academic discipline of philosophy in the case of legal philosophy vs. methods, problems, criteria of success viewed in terms of their potential to assist legal professionals with practical problems such as to enhance the well-being of law as a socially valuable practice in the case of jurisprudence. ${ }^{14}$

As Cotterrell's discussion proceeds, the stacking up of several and various qualities on each side of the alleged legal philosophy/jurisprudence dichotomy does not, to my mind, clearly determine the demarcation he seeks. Moreover, I suspect that we ought not and likely cannot distinguish between, 'legal philosophy' and 'jurisprudence' in the manner he proposes. For my own part, I doubt that there is any significant disciplinary division of the kind Cotterrell envisages which can and should be based on (i) the character of the audience purportedly addressed; (ii) the aspects of law focused upon and character of the problems tackled, differentiated in terms of their abstractness and purely philosophical interest vs. their institutional and practical complexity; or (iii) the alleged disciplinary credentials, and methods of inquiry, by which these enterprises are respectively 'validated.' ${ }^{15}$

Re. (i): all explanations, interpretations, and accounts of legal phenomena are, in certain senses, audience-dependent, and their success audience-relative. Both those aspects of legal phenomena focused upon, and the way in which they are explained, will vary depending on what the explanation is trying to achieve, and who it is trying to convince, or provoke further thought amongst. For example, an explanation of Ronald Dworkin's theory of legal reasoning aimed at provoking further self-reflection amongst judges as to the judicial task might focus more on case law where, according to Dworkin, the constructive interpretation method can be found, and what it would require can be illustrated; whereas an explanation of Dworkinian legal reasoning, and how answers to complex legal, political and moral questions are generated according to it, aimed at legal, political or moral philosophers might focus on Dworkin's claims regarding the truth and objectivity status of the propositions of law emerging from constructive interpretation, and on Dworkin's attempts to elide any questions implicating the meta-ethical status of those legal propositions. Often, when we try to explain something, we focus on some aspect of it with which our particular audience is likely to be familiar, and seek explanatory examples, analogies, avenues into the precise examination of the issues and reciprocal comparisons involving phenomena which that audience already knows and understands reasonably well.

\footnotetext{
11 Ibid passim, but see especially 42-3, 54-5.

12 Ibid passim, but see especially $50-3$.

13 Ibid 41, 43. I have difficulty in fully understanding this aspect of Cotterrell's thesis, and, in particular, understanding the character of the 'validation' relation he mentions.

14 Ibid passim, but see especially at 42, 46-7, 51-3, 55.

15 Ibid 41 and 43.
} 
In light of these points, a full specification of the criteria of success of any given account of law's character must include aptness and cogency of explanation in relation to the particular audience addressed. This, however, is a general point regarding all explanations, including all explanations of the character of law, thus such audience-sensitivity would be a criterion of success as applicable within Cotterrell's 'jurisprudence' as it would be within his 'legal philosophy', and hence would be ill-fitted to serve as a demarcation line between them. Granting, purely arguendo, some distinction between these enterprises, the puzzles addressed by and within each enterprise would need to be tackled, explained and resolved differently for a host of different audiences within legal philosophy, and for a host of different audiences within jurisprudence, rendering the 'legal philosophy is addressed only to academic philosophers' vs 'jurisprudence is addressed only to legal theorists and professionals steeped in the practice of law' purported demarcation line reductive and implausible.

Moreover, as the example above involving Dworkinian constructive interpretation illustrates, shifting the direction of approach, and/or mode of illustration and explanation of an issue in order to be appropriately audience-specific, does not, of itself, indicate that we have even changed topic, let alone that we have crossed over into a whole different discipline or sub-discipline. In that example, all the types and modes of explanation I mentioned could be good explanations of the same thing, ie Dworkinian constructive interpretation. They differ only in their emphasis, and in the route the explanation takes, and serve to remind us of the point that when we seek to understand something ourselves, or to explain it to others, we must work with and give due attention to where we already are in our knowledge of the phenomenon in question, and of cognate phenomena, and must start from where we already are and build bridges to further understanding from there. ${ }^{16}$

Re. Cotterrell's attempted demarcation (ii) above: accounts of the character of law, however abstract they are, and whatever level of generality of insights they offer, must, in order to be successful, be accounts of the character of law, ie the character of an actually existing social institution having profound effects on the reasoning processes, life chances, and social and political world of those living in law-governed societies. All theories of law - be they abstract or concrete, general or particularistic - to have any chance of success, must necessarily address, and unravel, puzzles regarding the social practice and institutions of law in all their complex social and institutional reality. This being so, this rendering of Cotterrell's legal philosophy/jurisprudence distinction - ie that the former addresses abstract problems far-removed from legal practice, solely in virtue of their intrinsic philosophical interest and that the latter addresses actual institutions and practices of law, and juristic experience in all its practical complexity ${ }^{17}$ - is based on a problematic, indeed perhaps an impossible, dichotomy. As I noted above in discussing audience-dependence, explanations of the same phenomena may start in different places, and explain things in different ways, ways that are apposite to the existing knowledge base and familiar points of reference and understanding of the relevant audience. This may result in explanations of the same phenomena varyingly significantly in content and structure, but this valuable (and inevitable) form of pluralism, which we ought positively to embrace as legal philosophers, in no way supports the view that only some of the explanations in question are focused on the social practice and institutions of law in all their complex reality. If an

\footnotetext{
${ }^{16}$ I touch on some points relevant to this issue in J Dickson, 'The Central Questions of Legal Philosophy' (2003) 56 Current Legal Problems 63. These points will be explored at much greater length in my 'monographin-progress', Dickson (n 3).

17 Cotterrell (n 6) passim, but see especially 41-3, 50-3.
} 
account of the character of law which purports to offer illuminating insights about law, and to improve our understanding of it, does not engage deeply and systematically with law's social and institutional complexity, then its problem is not that it is 'legal philosophy' rather than 'jurisprudence'; its problem is that it is a very bad account of the character of law and, in extreme cases, that it is not an account of the character of law at all.

Re. attempted demarcation (iii) above: it is difficult to grasp the sense in which there could be 'validating' credentials for accounts of anything beyond those which the relevant accounts themselves can muster, persuade us of, and draw argumentative support for in their (for want of a better term) own methodological foundations, and in the accuracy and explanatory power of the substantive accounts of law which proceed from those foundations. In my view, there is a necessary interplay between methodology and substance in legal philosophy, and it is a mistake to think of a jurisprudential 'methodology' as some kind of free-floating disciplinary mode, the appropriateness of which, and/or the provenance of its 'validating' 'credentials', can be identified and justified in some sense apart from and prior to the cogency and explanatory power of the substance of the explanations offered by the accounts of law concerned. ${ }^{18}$ Moreover, the idea that academic philosophy - with its long and varied history of tendentious disputation as regards the proper questions, aims, approaches, techniques and methods of the discipline, and as regards the status and cogency of those insights it purports to deliver - might provide monolithic and univocal, 'theoretical or methodological protocols' ${ }^{19}$ capable of univocally 'validating' aspects of itself, let alone the cognate discipline of legal philosophy, seems highly unlikely.

Much more could be said as regards the above points, and as regards many of the other important matters Cotterrell discusses in 'Why Jurisprudence Is Not Legal Philosophy'. However, for the purposes of the present discussion, we must 'zoom out' from my doubts regarding Cotterrell's thought-provoking but problematic attempt at framing a meaningful or appropriate legal philosophy/jurisprudence distinction, and reconnect with the broader point that I mentioned above, ie that, in my view, the terms 'legal philosophy', 'philosophy of law' 'jurisprudence', and 'legal theory' are largely interchangeable, and that it is best, especially at the outset of inquiries into the character and criteria of success of our discipline, to adopt as broad a working definition of legal philosophy as possible. Such an approach is vital in order to leave appropriately on the table the various kinds of questions which such inquiry must address, and to accommodate the valuable pluralism in inquiry which law's complex and multi-faceted character demands.

In this spirit, then, by 'legal philosophy', I mean no more or less than any illuminating inquiries into and accounts of various aspects of law's character. This extremely 'broad church' understanding of legal philosophy makes room for various important thoughts about the character of law, and of its theory, which legal philosophers should embrace. For instance, it allows for considerable pluralism without conflict or incompatibility between at least some theories of law which may superficially appear to be competitors. Law, on this vision, should be thought of as a complex, multi-faceted phenomenon, and various, and various combinations of, those facets, can be illuminated by theoretical shafts of light striking different parts of it from different directions, and in different combinations. Such theories of aspects of law can each potentially reveal important and significant truths

\footnotetext{
${ }^{18}$ See J Dickson, Evaluation and Legal Theory (Hart Publishing, 2001), chs 1 and 7 for further discussion.

${ }^{19}$ Cotterrell (n 6) 53.
} 
about law's character, and can increase the elucidatory power of legal philosophy as a whole.

Moreover, some of law's many and complex facets, and the extent of their importance and relevance in terms of legal, social and moral life in law-governed societies do not become apparent until certain historical, social, and intellectual contexts make them so. This thought opens the door to the key point that the questions of legal philosophy arise in and change over time in response to changing circumstances, contexts, and puzzles, rendering the task of legal philosophy rich, diverse, and never-ending. ${ }^{20}$

All this said, however, it is important to emphasize that the above points, even cumulatively, do not add up to some implausibly compatibilist picture of jurisprudential inquiry and debate. Many theories of law can and will conflict with one another, and the conflict may be illuminating and significant, as well as real. However, in order to confirm that apparent, or, in some cases, merely rumoured, conflicts between theories of law are real, and to gain valuable understanding of the conflict in question, and of what is revealed by it and can be learned from each position within it, we will need to understand precisely, and examine carefully, the respective propositions regarding law's character which any given candidate incompatible theories propound. And, as I argue in the next section, this is a task rendered the more difficult when significant parts of the relevant legal philosophical discourse feature caricatures, 'straw man' renderings of positions, inaccurate and imprecise characterisations of others' views, and a febrile and sometimes aggressively adversarial tone and style of argumentation.

\section{(B) Of Devils}

Legal philosophy, then, in my view, encompasses any illuminating inquiries into and accounts of the character of law. This renders our discipline a very broad church, which may include many different foci of inquiry, be addressed to a variety of audiences, address many different sub-sets of law's properties, use different evidential and argumentative methods to establish conclusions, and which will change in its character and focus as new puzzles and concerns arise over time. Within this diverse and pluralistic understanding of legal philosophy, particular works of particular legal philosophers can and inevitably do choose to focus on certain questions and puzzles about law, and to address them in particular ways.

For my own part, I have chosen in much of my work to focus on matters relating to the philosophy of legal philosophy (or the methodology of legal philosophy) and have espoused a particular approach to such matters. That approach - which is here termed 'indirectly evaluative legal philosophy' (IELP) - attempts to eschew yet another distinction sometimes invoked in the philosophy of legal philosophy, and indeed another distinction which I find very misleading and damaging in terms of fostering open and constructive engagement between theorists working in this area: the ostensible distinction between 'descriptive' theories of law, and 'normative' or 'evaluative' theories of law.

As I have argued elsewhere, this distinction does not make sense or have useful purchase as it stands, for all inquiries into and accounts of aspects of law are evaluative in

${ }^{20}$ These features of legal philosophy are discussed further in section 3 below and are discussed in Dickson, 'The Central Questions of Legal Philosophy' (n 16). 
character, rendering 'descriptive', with its value-free connotations, a misleading misnomer in this context. ${ }^{21}$ Indeed a key tenet of IELP is that we can, should, and must, in order to have explanatorily adequate theories of law, evaluate what are law's important and significant features, and must use those and related evaluative judgements in justifying and defending our theories of law, and in revealing their relevance to matters of contemporary social, moral and intellectual concern. That said, however, IELP also holds that there is an important distinction between different kinds or different senses of evaluation featuring at different stages in theories of law, and, for reasons discussed in section 3 below, strongly advocates that we postpone, and approach cautiously, morally evaluating, and certainly morally justifying law, until we have a non-morally-evaluative-or-morally-commendatory account of law's most significant and important properties, and the relevance of those properties to our social, political and moral lives. ${ }^{22}$

Arguably, if legal philosophers took an appropriately pluralistic view of the many facets of jurisprudential inquiry of potential value within the broad church of our discipline, then they ought to welcome this methodological approach as one interesting and potentially illuminating possibility amongst others, and should seek to explore how other methodological approaches might relate to, complement, and enhance it. Indeed, in some quite obvious respects, the kind of 'indirectly evaluative' approach sketched above lends itself to relations of complementarity with at least some other theories of law, and indeed certain other academic disciplines, propounding as it does only a relative separation from, and a relative and temporary postponement of, theoretical approaches seeking to morally evaluate, justify, criticize or attempt to improve law. IELP specifically envisages, and welcomes, a plurality of distinct forms and stages of jurisprudential inquiry, and counsels that it may benefit our ultimate understanding and moral scrutiny of law if we approach it in theoretical stages, in a way which makes room for different sorts of theories to play various roles in our understanding and scrutiny of law overall. ${ }^{23}$

This view, however, is subject to the following qualification. Although I wish to emphasize that our discipline represents a broad church, and that we should seek complementarity and constructive theoretical pluralism where it is possible to do so, it is also vital in reaching an accurate and appropriately nuanced understanding of the character of and relations between theories of law, to avoid over-emphasizing the possibilities of compatible, or even mutually supporting and enhancing, co-existence amongst a plurality of theories of law. In particular, it is important to acknowledge that certain aspects of some morally evaluative approaches to understanding law, would very likely not be compatible with some aspects of the indirectly evaluative approach I champion, and that important disagreements would remain, even after some of the current excessive polarization and mischaracterizations afflicting the debate are dispelled. To explain further: some critics of the 'indirectly evaluative' approach to legal philosophy do not accept that there can be a 'first stage' in the inquiry into law's nature which it is possible to undertake in a nonmorally-evaluative or a non-morally-commendatory way. Such critics claim that in the very delineation of the subject matter of our legal philosophical inquiries, and in the formation and elaboration of the concepts we use in our jurisprudential theories, we must necessarily

\footnotetext{
${ }^{21}$ See Dickson, 'Methodology in Jurisprudence: a critical survey' (n 2), Dickson, Evaluation and Legal Theory (n 18), J Dickson, 'Descriptive Legal Theory' (2006) IVR Encyclopaedia of Jurisprudence, Legal Theory and Philosophy of Law, available at: http://ivr-enc.info/index.php?title=Descriptive_Legal_Theory

22 See Dickson (n 18) chapters 2-4 and 8, and section 3 below.

${ }^{23}$ See further section 3 below.
} 
make morally evaluative and, for some theorists, morally commendatory, judgments regarding the nature of law and the concept of law. As such, these approaches counsel the adoption and pursuit from the very outset of jurisprudential inquiries of goals such as to show law in a morally good light, and/or to morally justify the duties law purports to impose, and/or to explain its moral obligatoriness in virtue of its allegedly unique ability to secure morally valuable ends.

Many such morally evaluative methodological stances - such as those pioneered and developed by Ronald Dworkin, John Finnis, Jeremy Waldron, Maris Köpcke Tinturé, Stephen Perry and Nicos Stavropoulos, employ rich, subtle arguments regarding the character of evaluative concepts in general, and the character of the concept of law in particular. As should emerge from an appropriately nuanced examination of such approaches, they offer many and varied challenges to my own type of methodological view, as well as, I suspect, revealing much valuable and under-emphasized common ground as regards some matters which are falsely or exaggeratedly believed to be in dispute between and amongst us.

Unfortunately, however, the current state of jurisprudential debate on certain methodological issues seems unlikely to foster this kind of nuanced understanding of each other's respective positions. This is due, at least in significant part, to the way in which some of the relevant debates are being conducted, and, in particular, due to some theorists failing to adopt the kind of open, and jointly explorative, attitude which I believe necessary in order to sift truth from rumour, and reality from distortion, as regards points of accord and of disagreement between these different views of the correct 'philosophy of legal philosophy.' In my view, such failings are amongst the most pernicious 'devils' currently afflicting methodology debates within our discipline.

To select but a few of many possible examples, some theorists adopting a 'morally evaluative and commendatory from the outset' view of legal philosophy have characterised those holding a different view - eg those who, as I do, counsel against attempting to morally evaluate and justify law from the outset, and who advocate a different understanding of the role of evaluation in legal theory - as thereby espousing accounts of law which are: question-begging, and illegitimately circumscribe the agenda of jurisprudential inquiry; ${ }^{24}$ redundant, confused, and guilty of arbitrarily truncating the ambit of legal philosophy, thus illegitimately 'hiving off' to other disciplines some of jurisprudence's central questions; ${ }^{25}$ engaged in artificially and arbitrarily excluding certain moral and political considerations that are plausibly relevant to establishing the success of theories of law; ${ }^{26}$ seized of a bordering-on-the-dogmatic desire to bolster 'substantive legal positivism', and a fear of adopting a methodological stance which would undermine such positivism; ${ }^{27}$ captivated by uninteresting and sterile questions, addressed largely by persons who neither have, nor wish to attain, background experience, training, or familiarity with any other intellectual work or disciplines beyond their own depressingly narrow and self-referential jurisprudential

\footnotetext{
${ }^{24} \mathrm{~N}$ Stavropoulos, 'Obligations and the Legal Point of View' in A Marmor (ed), The Routledge Companion to Philosophy of Law (Routledge, 2012).

25 John Finnis, 'Law and What I Truly Should Decide' (2003) 48 American Journal of Jurisprudence 107; J Finnis, 'What is the Philosophy of Law?' (2012) 1 Rivista di Filosofia del Diritto 67.

${ }^{26}$ S Perry, 'Method and Principle in Legal Theory' (book review of Jules Coleman, The Practice of Principle: in Defence of a Pragmatist Approach to Legal Theory (OUP, 2001)), (2002) 111 Yale Law Journal 1757 at 1809-13.

${ }^{27}$ N Stoljar, 'In Praise of Wishful Thinking: A Critique of Descriptive-Explanatory Theories of Law' (2012) 6 Problema: Anuario de Filosofía y Teoría del Derecho 51, especially section III.
} 
world; ${ }^{28}$ problematically isolationist in their attempts illegitimately to inure jurisprudence from criticisms hailing from relevant neighbouring disciplines, turning it into a niche subject devoid of important questions or interesting answers; ${ }^{29}$ insulated from the outwardlooking curiosity appropriate to intellectual inquiry, riven with negative in-fighting of interest only to those already engaging in it, and guilty of engaging in aggressive debates characterized by a 'sharp shooter', point-scoring approach; ${ }^{30}$ positions which frequently fail on their own terms, are not consistently followed through, and display serious shortcomings when they are followed through; ${ }^{31}$ guilty of ignoring and/or neglecting important intellectual resources from political philosophy, political theory, and from the history of legal philosophy, resulting in repetitive, internecine point-scoring in ever-decreasing academic circles; ${ }^{32}$ and are hence understandably perceived by some as engaging in, 'largely an inbred word game, of little interest to those who are really interested in law. ${ }^{33}$

Jurisprudential tempers seem to be running a little high in this area! So many and various are the accusations levelled by the above commentators that it is difficult to know how to proceed in discussing them. For present purposes, I will pick out just two of the themes which seem repeatedly to emerge from this febrile discourse.

The first theme focusses on the style of argument and on the attitude towards intellectual inquiry which those methodological approaches - such as my own - excoriated by the various commentators surveyed above allegedly exhibit. Accusations of over-hasty, hostile dismissals of alternative positions, and of aggressive yet sterile point-scoring and 'sharp-shooting' would fall into this category.

${ }^{28} \mathrm{R}$ Dworkin, 'Thirty Years On, a book review of Jules Coleman's The Practice of Principle: in Defence of a Pragmatist Approach to Legal Theory' (2002) 115 Harvard Law Review 1655, especially section IV; R Dworkin, 'Hart's Postscript and the Character of Political Philosophy' (2004) 24 Oxford Journal of Legal Studies 1, especially the concluding section.

${ }^{29} \mathrm{D}$ Priel, 'Positivism and the Separation of Law and Jurisprudence' http://papers.ssrn.com/sol3/papers.cfm?abstract_id=1951912 ; D Priel, 'Free Floating from Reality' (2008) 21 Canadian Journal of Law and Jurisprudence 429, especially section 5.

${ }^{30}$ Cotterrell (n 6) passim. It is important to note that Cotterrell presents some, though not all, of the above criticisms, as applying more typically to an approach to legal philosophy which he refers to as "contemporary legal positivism' rather than to legal philosophy as a whole (ibid 45-9), and as less his own view, and more 'a collation of critiques from within the ranks of legal philosophers themselves' (ibid 45). Some might take the view, therefore, that I am mistaken in understanding this aspect of his views as directed towards the kind of approach to legal philosophy that I advocate. There are a number of difficulties with this latter view, however. For instance, contra Cotterrell, the 'contemporary legal positivism' to which he refers is not a methodological stance at all, but rather marks commitment to only one main proposition about the nature of law. Additionally, Cotterrell presents, and, to my mind at any rate, presents as at least prima facie plausible, some trenchant criticisms of the character and modes of inquiry of legal philosophy in his collation of the views of others, and explicitly mentions the work of eg Joseph Raz, John Gardner, and myself, as being situated within the tradition of contemporary legal positivism against which the most strident of the collated critiques seem directed (Cotterrell (n 6), at 45-9 and in notes 22, 33, and 37). All this said, as was already mentioned ( $\mathrm{n} 6$ ), there is much to admire, and much that I agree with, in Cotterrell's article, and I regret that I cannot fully examine all aspects of his position here.

${ }^{31}$ M Köpcke Tinturé, 'Positive Law’s Moral Purpose(s): Towards a New Consensus?' (2011) 56 American Journal of Jurisprudence 183.

32 Jeremy Waldron, 'Legal and Political Philosophy', in Jules Coleman and Scott Shapiro (eds), The Oxford Handbook of Jurisprudence and Philosophy of Law (OUP, 2002), ch 9.

33 Jeremy Waldron, 'Can There Be a Democratic Jurisprudence?' (2009) 58 Emory Law Review (2009) 675, at 677. $\mathrm{nb}$ in this piece, Waldron cites this view not as his own, but as one which is understandably held by some others, given the state of contemporary jurisprudence. He also notes that, 'in some moods' (ibid), he has sympathies with such views, see further Waldron (n 32). 
The second theme has more to do with the substance of the methodological positions espoused, with the complainants above claiming that methodological approaches - again, such as my own - which differ from theirs on the issue of the role of moral evaluation in jurisprudential inquiry are uninterested in, unqualified as regards discussing and shamefully neglectful of law's moral and political aspects, and, concomitantly, are reluctant to and/or incapable of engaging in, or indeed even engaging with, moral, political, and social philosophy. Accusations such as some of those made by Jeremy Waldron and, especially, those made by Ronald Dworkin in the works quoted above, fall into this second category.

As regards the first theme identified above, the old adage concerning pots, kettles, and black comes inevitably to mind. To accuse other legal philosophers, indeed in some cases entire theoretical approaches and traditions, of engaging in hostile dismissals of other positions, and of adversarial point-scoring and 'sharp-shooting' by means of oneself hurling polarizing, inaccurate, and unsubstantiated brickbats across the fence at them, seems to me a distinctly odd way of making that particular point, and indeed an unhelpful way of making any point in academic discourse. I share wholeheartedly the view that engaging in intellectual argument and debate in this way is depressingly negative and anathema to the spirit of fascinated puzzlement and open, exploratory inquiry which should imbue our work as legal philosophers. ${ }^{34}$ But I strongly reject the view espoused by some of those commentators mentioned above, that any one jurisprudential position, legal philosophical approach, school of thought, tradition of argument, or given group of theorists, hold the monopoly, or even the dominant market position, as regards this kind of damaging behaviour, in either written or oral form. What is important here is that all legal philosophers, of whatever stripe or leaning, should 'cast out' this particular 'devil' and conduct ourselves in a way which is considerably better than this, so that we do not lose sight of the common intellectual spark and sense of wondering puzzlement which drew us to pursue the work that we do in the first place. In this respect, I hold fast to Robert Nozick's view in his wellknown 'Introduction' to Philosophical Explanations, that we should eschew 'coercive philosophy', not least because:

'Philosophical argument, trying to get someone to believe something whether he wants to believe it or not, is not, I have held, a nice way to behave towards someone; also, it does not fit the original motivation for studying or entering philosophy. That motivation is puzzlement, curiosity, a desire to understand, not a desire to produce uniformity of belief. ${ }^{35}$

The second theme identified above - that certain jurisprudential methodologies which counsel against approaching law as a morally good phenomenon from the outset - again, such as the indirectly evaluative approach I espouse - are uninterested in, unqualified as regards discussing, and/or shamefully neglectful of law's moral and political aspects, and, concomitantly, are reluctant and/or incapable of engaging with moral, social and political philosophy - involves charges of a different character. But it shares with the first theme a tendency to distort and mischaracterize, and it does not take adequate cognizance of the pluralism, diversity, variability, and breadth of legal philosophical inquiry which is alive and kicking in the work of our peers. Contra some of the febrile accusations surveyed

\footnotetext{
${ }^{34}$ Helpful email correspondence has confirmed that Roger Cotterrell and I are in agreement on this point. See also notes 6 and 30 above.

35 Robert Nozick, Philosophical Explanations (Belknap Press of Harvard University Press, 1981), 'Introduction' 13.
} 
above, many examples spring readily to mind of jurisprudential work which counsels against attempting to morally evaluate and/or morally justify law from the outset, but which nonetheless hails from legal philosophers who are hugely knowledgeable as regards moral, political, and social philosophy, and who have deployed their talents in these respects in their work in philosophy of law, and far beyond, eg in their work in moral, political and social philosophy itself. ${ }^{36}$

It is unfortunate in the extreme that the polarizing adversarialism noted above has come to hold such sway in debates in jurisprudential methodology. Moreover, for present purposes, attempting a point-by-point rebuttal of the many and various accusations canvassed above hardly seems an appropriate way of moving beyond such unproductive standoffs. In the remainder of this article, I thus take a different tack, offering a response to various of the commentators mentioned above in the form of presenting my alternative vision of the facet of jurisprudential inquiry which has most puzzled and fascinated me in my own work.

\section{SETTING OUT MY STALL: INDIRECTLY EVALUATIVE LEGAL PHILOSOPHY}

In the remainder of this article, I develop and begin to defend an account of the aims, motivations, character and criteria of success of the approach to legal philosophy which I espouse, and which I refer to here as Indirectly Evaluative Legal Philosophy (IELP). Important as it is to better understand the character of this facet of jurisprudential inquiry, it is also vital to keep in mind that it is but one facet of such inquiry as a whole. IELP is firmly committed to the value of other facets of jurisprudential inquiry, and adopts an optimistic and open stance as regards the potential ability of many such facets of legal philosophy to mutually complement, enhance, and augment one another. Of course, it must also be borne in mind that, as has been mentioned at several points in the discussion thus far, we should not espouse an implausible and unrealistically compatibilist picture of jurisprudential inquiry and debate. Many theories of law can and will conflict with one another, and the conflicts will prove illuminating and significant. In order to gain valuable understanding of the nature and importance of these possible conflicts, however, we must do better in our attempts to understand each other's respective positions regarding the character of law, and the character of legal philosophy. It is this spirit that I elaborate further below upon the character of Indirectly Evaluative Legal Philosophy (IELP).

IELP then, seeks to:

- identify and explain significant, important, and illuminating aspects of the nature of law, and consider what it is for law to have a nature, and how truths about its nature are to be ascertained

- understand and be sensitive to the ways in which the questions of legal philosophy arise in and change over time

\footnotetext{
${ }^{36}$ See eg, all by Joseph Raz: The Morality of Freedom (Clarendon Press, OUP, 1986); Engaging Reason (OUP, 1999); The Practice of Value (OUP, 2005); From Normativity to Responsibility (OUP, 2011); all by Leslie Green: 'Kant's Liberalism: A Reply to Rolf George' (1988) 27 Dialogue 207; The Authority of the State (Clarendon Press, 1990); 'Two Worries about Respect for Persons' (2010) 120 Ethics 212; 'Sex-Neutral Marriage' (2011) 64 Current Legal Problems 1; Wil Waluchow, The Dimensions of Ethics (Broadview Press, 2003); W Waluchow, A Common Law Theory of Judicial Review: The Living Tree (Cambridge University Press, 2007); W Waluchow, 'Constitutionalism in the European Union: Pipedream or Possibility?' in Julie Dickson and Pavlos Eleftheriadis (eds) The Philosophical Foundations of European Union Law (OUP, 2012). Nb there are so many relevant examples that inevitably I can offer only a small selection here.
} 
- adequately account for, and explain the relevance of, the self-understandings - in terms of the concept of law and related concepts - of those who are subject to, create, and administer the law

- adopt an approach which resists premature and/or immoderate veneration of law, by proceeding from what we might call an 'attitude of due wariness' regarding law, and by postponing, and, in a certain sense, limiting, the role of moral evaluation in our theories of law, until certain questions have been addressed

- facilitate and engender moral and other evaluation, criticism and reform of the law, tasks which are a vital part of legal philosophy

Tenet \#1: IELP seeks to identify and explain significant, important, and illuminating aspects of the nature of law, and consider what it is for law to have a nature, and how truths about its nature are to be ascertained

Above, I have argued in favour of a 'broad church' view of legal philosophy: an approach which admits of considerable and enriching pluralism. In the course of the discussion, I also sought to debunk what I regard as some unhelpful attempted demarcation lines, and misleading purported distinctions and characterisations, currently featuring in some debates regarding the philosophy of legal philosophy. However, notwithstanding my firm commitment to these points, in my view, there is nonetheless a different distinction that we do well to keep in view, and to consider carefully (although not uncritically), when we theorise about law, and when we theorise about theorising about law. The distinction I have in mind here is that between:

(i) inquiries into the nature of law, which seek to identify and explain what is essential, or necessary, to something being law, and,

(ii) inquiries focusing on what is contingent about law, ie on that which can vary between times and places, without such variations determining whether or not something is law.

This distinction, rendered necessarily briefly for present purposes, features relatively frequently in jurisprudential discourse on the philosophy of legal philosophy. Some legal philosophers appear to embrace the distinction, and position their work, or, to be more precise, certain parts of their work, on one, ${ }^{37}$ or the other, ${ }^{38}$ side of it. There is also, of course, no bar to legal philosophers regarding some parts of their work as focusing on law's nature, and other parts of their work as engaging with what is variable and contingent about law, and viewing each of these enterprises as important and valuable. ${ }^{39}$

Others, however, harbour considerable doubts that the distinction does actually demarcate two viable enterprises, contending that it is implausible, and perhaps impossible, to conceive sensibly of law having a nature, or having essential properties, which theories

\footnotetext{
${ }^{37}$ Theorists conceiving of their work, or parts of their work, as concerning the nature of law, include (amongst many others) J Raz, 'Can There Be a Theory of Law?' in J Raz, Between Authority and Interpretation (OUP, 2009), chapter 2; N Stavropoulos, 'Legal Interpretivism', in the Stanford Encyclopaedia of Philosophy (original article 2003; substantially revised 2014), available at http://plato.stanford.edu/entries/law-interpretivist/ ; S Shapiro, Legality (Harvard University Press, 2011).

38 Theorists who regard aspects of their work as concerning law's contingent properties, and who consider investigations into contingent and variable aspects of law to be extremely valuable include (amongst many others) Michael Giudice, 'Analytical Jurisprudence and Contingency', in M Del Mar (ed) New Waves in Philosophy of Law (Palgrave Macmillan, 2011) 58; Cotterrell (n 6).

${ }^{39}$ Such an outlook has been manifest in various forms and at various times in the work of eg Elspeth Attwooll, Michael Giudice, Leslie Green, William Twining and many others.
} 
of law might even attempt to ascertain. ${ }^{40}$ For some theorists holding this latter view, law, a man-made artefact, emerging from social and institutional facts and processes, and partconstituted by the attitudes of people towards those facts and processes, just does not seem like the kind of thing capable of possessing necessary features or essential properties which make it into what it is.

My own view is that each wing of the distinction - inquiries into the nature of law, and inquiries into law's contingent properties - does indicate a possible, and valuable, theoretical endeavour as regards thinking about law. The distinction itself is also important, in that it allows us to try to understand what does, and what does not, make law into what it is, without losing sight of the importance of both sorts of features of law in advancing our understanding of it. What is needed is careful further investigation into exactly what each wing of inquiry commits us to, in terms of the aims and criteria of success of our various theories of law. We should also be open to the possibility that, upon such further investigation, we will find that the distinction is neither as clear-cut, nor as polarizing in terms of different kinds of legal theoretical endeavour, as may appear upon first encounter. Crucially, in considering this issue, we must eschew careless and unsubstantiated judgements concerning the relative importance of each type of inquiry, or conduct the work we choose to focus on in such a way as to, even unintentionally, assert or imply the intellectual superiority of one to the denigration of the other. Furthermore, we must not erroneously assume that theorists must declare themselves 'for' one type of enterprise over another, as if these various facets of jurisprudential inquiry were mutually exclusive, in themselves, or in the career of any particular legal philosopher.

Indirectly Evaluative Legal Philosophy is just one facet of inquiry within this pluralistic disciplinary scene. As the rendering of tenet \#1 above indicates, it is primarily concerned with identifying and explaining the nature of law, ie those features of law which make it into what it is. Accordingly, there are several puzzling issues to be investigated and explained by Indirectly Evaluative Legal Philosophy. As was noted above, a significant number of legal philosophers, of considerably varied theoretical leanings, proffer their theories as theories of the nature of law. What do such theorists mean when they claim to have identified and explained aspects of law's nature? What, precisely, are such claims about, and what would it take successfully to establish their truth? Is law an artefact concept, and, if so, does the character of artefact concepts preclude their having a nature, and having essential properties? How should we go about ascertaining truths about the nature of law, and/or the concept of law? Is there a role for conceptual analysis in this regard, and/or for linguistic analysis, and/or certain empirical and experimentalist approaches? Should legal philosophy be seeking knowledge of the concept of law, the nature of law, both, or neither?

IELP's strong emphasis on identifying and explaining law's significant and important features, and its claim that it is necessary to make indirectly evaluative judgements in order to do so, are also key to the character of this methodological stance. ${ }^{41}$ IELP does not attempt some value-free 'flat' description of law, in which the theorist casts a passive and invariantly focused eye over the terrain of law and merely describes - or perhaps 'records' captures it better - all that s/he sees. ${ }^{42}$ All theories of law are, inescapably, evaluative in

\footnotetext{
${ }^{40}$ See eg Brian Leiter, 'The Demarcation Problem in Jurisprudence: A New Case for Skepticism' (2011) 31 Oxford Journal of Legal Studies 663; Frederick Schauer, 'On the Nature of the Nature of Law' (2012) 98 Archiv für Rechts- und Sozialphilosophie 457; Brian Tamanaha, "What is "General" Jurisprudence? A Critique of Universalistic Claims by Philosophical Concepts of Law’, (2011) 2 Transnational Legal Theory 287.

${ }^{41}$ This point was also discussed in section $2 \mathrm{~B}$ above.

${ }^{42}$ See also the discussion at the beginning of section 2 above, and in Dickson (n 2), section II, on this point.
} 
character, and this is not in dispute. In contention are much more interesting questions such as: 'evaluative in what sense?', and 'evaluative in what sense at what stage of the inquiry?' IELP seeks to elucidate law: to illuminate particular aspects of it; to identify and explain law's important and significant features, and their impact upon the lives of those within law's purview; and to light the way for its moral evaluation, criticism, and reform.

\section{Tenet \#2: IELP seeks to understand and be sensitive to the ways in which the questions of legal philosophy arise in and change over time}

The philosophy of legal philosophy that I espouse emphasizes and seeks to explain the senses in which the questions of legal philosophy, and the theoretical accounts which they inspire, arise in and change over time, in response to changing interests and concerns. ${ }^{43}$ This feature of legal philosophy should encourage us to think differently about the doubts entertained by some legal theorists at times, and perhaps all of us on occasion!, regarding whether any progress has occurred, or will ever occur, in legal philosophy. ${ }^{44}$ Reflection on the history of jurisprudence; on the questions it has addressed, and the many and various answers offered by theorists at different times, understandably drives some to ask: if legal philosophers have been addressing the same questions for hundreds or indeed thousands of years, then shouldn't some conclusive and widely accepted knowledge have been attained by now, at least as regards some of those questions? And if this has not been the case, doesn't it indicate that there is a problem with the questions we keep asking, and the means by which we continue to try to answer them? ${ }^{45}$

This, however, is to misunderstand the character, aims, and criteria of success of legal philosophy. The approach to legal philosophy which I champion seeks to emphasize and explore the point that the questions of legal philosophy have not remained the same throughout the history of the discipline, but rather arise in and change over time, in response to changing interests and concerns. For example, as regards the past history of jurisprudence, we might think of the 1958 Hart-Fuller debate concerning the factors which bear upon the identification of valid law, and the normative consequences of law so identified. These issues were, of course, thrown into sharp relief and rendered vitally important to understand and explain by events occurring during and after the Second World War and the Nuremberg trials. ${ }^{46} \mathrm{~A}$ more recent example might be found in the fluctuating jurisprudential interest in the theory of legal systems. The late 1960s and early to mid-1970s witnessed a flurry of legal philosophical interest in questions surrounding the identity of legal systems (such as which criteria determine when norms belong to one and the same legal system, how we should understand the limits of legal systems and their relations with norms from outside the system in question) and their continuity through time (such as how do we know when an existing legal system has been replaced by a new one, when one legal system has split into two, or two such systems joined into one?). A focus on such questions was prompted in part by puzzles generated by the journey to political independence taken by

\footnotetext{
${ }^{43}$ See the close of section 2A above, and Dickson (n 16) for further discussion of this point.

44 See eg Leiter (n 40).

45 Ibid, especially at 2-8 and 15.

46 See HLA Hart, 'Positivism and the Separation of Law and Morals' (1958) 71 Harvard Law Review 593; L Fuller, 'Positivism and Fidelity to Law - a Reply to Professor Hart' (1958) 71 Harvard Law Review 630.
} 
certain former colonial nations. ${ }^{47}$ Once these developments largely ran their course, interest in the theory of legal systems waned dramatically, and, arguably, without many of the relevant issues having been understood satisfactorily. ${ }^{48}$ However, in recent times, the ongoing proliferation and increased importance of forms of non-state and non-single-legalsystem legality - such as is found in the supranational legal arrangements of the contemporary European Union, and in other areas of international and transnational law - has rejuvenated scholarship on the character, puzzles, and applicability of the concept of a legal system, and this topic has become avidly debated once again. ${ }^{49}$

The consequent fluidity, change, innovation, and diversification as regards the foci of jurisprudential inquiry ought not to be perceived as weakening legal philosophy's credentials in some way, but rather as indicative of enduring disciplinary vibrancy. An adequate philosophy of legal philosophy, however, thus needs to take as part of its task the closer consideration and investigation of:

(a) the precise sense in which, and means by which, the questions and foci of legal philosophy arise in and change over time;

(b) why and how the phenomenon countenanced in (a) does not, of itself, undermine the view that legal philosophy seeks to identify and explain truths about aspects of the nature of law, or threaten the idea that accounts of the nature of law can be better or worse in terms of their accuracy and elucidatory power; and

(c) the phenomenon that some disputes between legal philosophers assume the form that they do because theorists are asking different questions, or asking similar questions but with different emphases, and in response to different interests and concerns. In considering more closely this aspect of legal philosophical debate, we can better focus precisely what is, and what is not, at issue between theorists, and gain greater insight into the character and importance of certain disputes.

Further exploration of these points will reveal more fully the sense in which progress in legal philosophy does not take the form of an ever-accumulating body of conclusive and widely accepted knowledge. Rather, good legal philosophy generates a host of new and diverse further questions, even as it attempts to move forward with those it initially set itself. This is an enormous strength, not a frustrating weakness, of the discipline.

Tenet \#3: IELP seeks to adequately account for, and explain the relevance of, the selfunderstandings - in terms of the concept of law and related concepts - of those who are subject to, create, and administer the law

According to IELP - though it is not alone in this view, which is shared by several other approaches to philosophy of law - a large part of the task of legal philosophy is to advance our understanding of ourselves by illuminating various inter-related legal concepts which

\footnotetext{
47 See eg AM Honoré, 'Reflections on Revolutions' (1967) Irish Jurist 268; JM Eekelaar, 'Rhodesia: the Abdication of Constitutionalism' (1969) 32 Modern Law Review 19; JM Eekelaar, 'Principles of Revolutionary Legality' and John Finnis 'Revolutions and Continuity of Law', both in AWB Simpson (ed), Oxford Essays in Jurisprudence, Second Series (OUP, 1973).

${ }^{48}$ A point noted by Joseph Raz in 'Two Views of the Nature of the Theory of Law: A Partial Comparison' (1998) 4 Legal Theory 249, at 258.

${ }^{49}$ See eg M Giudice and K Culver, Legality's Borders (OUP 2010); Detlef von Daniels, The Concept of Law From a Transnational Perpsective (Ashgate, 2010); M Giudice and K Culver, 'Not a System but an Order: An Inter-Institutional View of European Union Law', J Dickson, 'Towards a Theory of European Union Legal Systems' and G Letsas, 'Harmonic Law: The Case Against Pluralism', all in J Dickson and P Eleftheriadis (eds), Philosophical Foundations of European Union Law (OUP, 2012).
} 
those administering and living under law already use in characterizing law, and their experience of it. When legal philosophers come to try to identify and elucidate aspects of the concept of law, they are attempting to explain a concept which is already used by users of that concept to understand themselves and their lives in terms of law. Those in societies governed by law think and speak of issues such as who gets to make law, whether they are the correct group to do so, what input others should have as regards the law-making process, and whether the law so made is just, fair, and offers appropriate solutions to difficult social problems. They consider and contrast what law requires, and what morality, family obligations, or their religion requires, and are familiar with dilemmas created by the divergence of various normative standards simultaneously applicable to them in certain situations. They have a sense of law's mandatory character, of the consequences of breaking it, and of its potential for abuse, particularly by those whose task it is to create and administer it.

As a consequence, legal philosophy is constrained in the character of the explanations it gives: it must seek to elucidate law in a way which does adequate justice to how it is already understood, and is understood to feature in, the lives of those who create, administer, and are subject to it. This view is shared, in some form, by legal philosophers of many different stripes and theoretical commitments, including HLA Hart, Joseph Raz, Ronald Dworkin, John Finnis, Neil MacCormick and Brian Leiter. However, the appropriate interpretation of this hermeneutic requirement stands in need of further exploration and

elaboration. For example: 'Does adequate justice to' - a phrase I use above, and which features regularly in the work of others in this area - conceals many important and difficult questions. What, precisely, does this requirement amount to, especially given that, in my view, we should reject the notion that legal theorists merely undertake some kind of jurisprudential 'vox-pop' exercise and then reproduce in their theories existing self-understandings and attitudes of those living under law $?^{50}$ Being appropriately attuned and sensitive to the existing self-understandings of those living under law nonetheless leaves much work for the theorist to do, including making discerning and illuminating value judgements of various kinds, in order to separate the central from the peripheral, the morally relevant from the extraneous, the deeply held from the superficial, and in order to hew from the 'raw material' of those existing self-understandings, a coherent and convincing account of the character of law. ${ }^{51}$

But how far can and should legal theorists go in systematizing, rendering more coherent, interpreting and extrapolating from existing self-understandings, and what constraints are properly incumbent upon them as they do so? Can we ever legitimately depart from existing understandings of concepts vital to legal life? What are the proper limits of conceptual revisionism in this regard? We need a philosophy of legal philosophy which will tackle these difficult questions, as well as acknowledging and seeking to remedy the fact that the whole notion of 'self-understandings' is considerably under-explained in much of the relevant literature. Such an account must seek rigorously to interrogate this notion, and the constraints it imposes upon philosophy of law.

\footnotetext{
50 See eg Dickson (n 2).

51 Dickson (n 2) and J Dickson, 'On Naturalizing Jurisprudence: Some Comments on Brian Leiter's View of What Jurisprudence Should Become' (2011) 30 Law and Philosophy 477, offer further discussion of this point. It will be a key topic in Dickson (n 3).
} 
Tenet \#4: IELP aims to avoid premature and/or immoderate veneration of law, by proceeding from what we might call an 'attitude of due wariness' regarding law, and by postponing, and, in a certain sense, limiting, the role of moral evaluation until certain questions have been addressed

'Near 300 years has religion had her Luther. No Luther of jurisprudence is yet come; - no penetrating eye and dauntless heart have as yet searched into the cells and conclave of jurisprudence. ${ }^{52}$

Jeremy Bentham was discussing the archaic intricacies of the nineteenth century English law of evidence and judicial procedure when he penned the above cri de coeur. However, Bentham's zeal for demystifying law, and desire to 'draw aside that curtain of mystery which fiction and formality have spread so extensively over the Law', ${ }^{53}$ is manifest in both his writings on particular areas of law, and in his approach to constructing a general theory of law. ${ }^{54}$ One Benthamite approach to this matter with much to commend it is the adoption of a healthy scepticism regarding the character and claims of law. Bentham sought to strip away the cloak of moral veneration which he believed Blackstone and others had draped around law, in order that we might see clearly, and in the cold light of day, its character, and what exactly it was asking of us. Only then, with such a cool-headed and un-romanticized understanding of law in mind, would we be able effectively to undertake the vital task of evaluating and reforming it, with moral and social progress as our lodestar.

Indirectly evaluative legal philosophy seeks to develop and drive forward aspects of this Benthamite insight. Some important points should be noted at the outset. First of all, it is important to establish that a commitment to building a cool-headed account of law as it is, prior to, and relatively independent of, morally evaluating, criticizing and reforming it, is, contra some of the accusations labelled at such approaches, ${ }^{55}$ not symptomatic of an unmotivated attachment to some dry descriptivism as an end in itself. IELP is deeply concerned with the moral and other evaluation, criticism and reform of law. But it advocates approaching that moral evaluation and criticism via a somewhat indirect route.

Secondly, IELP does not, and does not pretend to, approach law from what we might call an uninvolved starting point. Rather, it is committed to holding what we might refer to as an 'attitude of due wariness' regarding law. Two key facets of law's character and operation prompt and justify such an attitude.

The first concerns the obfuscating character of the many rhetorical, symbolic, linguistic, and other 'tricks' that law has up its sleeve, which may serve to persuade us prematurely, and without sufficient rational assessment, of its moral value and obligatoriness. Law presents itself to us bedecked in archaic and baroque language, terminology, phraseology, and forms of address largely impenetrable to those not educated in its ways. Its most public face is shown in grandiose buildings; distinctive and often hierarchical court

\footnotetext{
${ }^{52}$ The Works of Jeremy Bentham, published under the Superintendence of his Executor, John Bowring (William Tait, Edinburgh, 1838-1843), volume VII, 'Rationale of Judicial Evidence', 270, concluding paragraph of footnote.

${ }^{53} \mathrm{JH}$ Burns \& HLA Hart (eds), The Collected Works of Jeremy Bentham: A Comment on the Commentaries and A Fragment on Government (OUP, 2008) 124.

${ }^{54}$ See eg HLA Hart, Essays on Bentham (Clarendon Press, 1982) 22-23.

${ }^{55}$ See section 2B.
} 
etiquette and procedure; and learned and sometimes bewigged-and-gowned judges and lawyers. Its associated nomenclature - 'Ministry of Justice', 'Royal Courts of Justice', etc. proclaims not only the importance of law's domain, but also law's august credentials within it: Ministries and Courts of Justice appear by their very name to be holding themselves out not merely as aspiring to, but as delivering, justice. Such features of law can generate an obscurantist fog around law, shielding it from criticism, and creating an air of mystery and majesty such as prematurely to convince us that law ought to be venerated and obeyed.

Secondly, in addition to its self-engendered air of moral venerability, the domain in which law operates, the way it characteristically operates, and the gravity of its possible consequences, also give us reason to approach law with an attitude of due wariness. Law claims comprehensiveness with regard to those areas of human life that it may regulate. It regulates matters of considerable moral and other importance to us; as individuals, and in terms of the societies in which we live. However, human history stands obvious and powerful witness to the fact that human beings, and the social institutions they create and administer, have given (and continue to give) legal shape to a range of morally repugnant social arrangements and forms of social organization. Moreover, when law and its officials get things wrong and fall into moral and other error, the consequences for us and for our societies are far more serious than when an individual goes thus astray. Law operates on a mass scale, applying itself compulsorily to whole population sets at a time. It characteristically comes with the backup of the full panoply of state coercion. Errors perpetuated by a social institution on this scale and with this character have the capacity to be wideranging, far-reaching and to have deep and sometimes catastrophic effects on the lifechances of those living under it. None of this is to ignore the fact that law can be - and often is - an instrument of tremendous social and personal good; it is merely appropriately to remind ourselves of its - and our - possible darker sides.

The above aspects of law's character justify approaching it with an attitude of due wariness. The stakes are high: if we are too quick to view law in the manner in which it presents itself, and lose sight of the large scale and catastrophic effects which may result from its premature and intemperate veneration, then we run tremendous moral and other risks, on our own behalf, and on behalf of the societies in which we live.

\section{Tenet \#5: IELP seeks to facilitate and engender moral and other evaluation, criticism} and reform of the law, tasks which are a vital part of legal philosophy

As has been noted at several points in this article, it is an unfortunate but pervasive misconception that a philosophy of legal philosophy which holds that we ought to seek a coolheaded and non-morally-evaluative account of law as it is, prior to, and relatively independent of, morally evaluating, criticizing and reforming law, is, thereby, exhibiting an unhealthy attachment to arid descriptivism as an end in itself, and is seeking illegitimately to insulate legal philosophy from neighbouring disciplines such as political, moral, or social philosophy. ${ }^{56}$ Nothing could be further from the truth. IELP is acutely concerned with those moral and other evaluative standards to which law should be held, and with the place of law in our practical reasoning processes and well-being. Indirectly Evaluative Legal Philosophy, however, differs from some other approaches, including from some 'morally evaluative from the outset' approaches to legal theory, in contending that such matters must be approached and answered in stages, and that a significant part of the work of identifying

${ }^{56}$ See section 2B. 
and understanding important features of law relevant to law's moral evaluation, can and should be done while postponing and limiting the role of moral evaluation in our theories until certain questions have been addressed, and a certain stage in the inquiry reached. ${ }^{57}$

On this view, the first 'stage' of our inquiries into the character of law ought not to be morally evaluative, and certainly ought not to be morally commendatory or justificatory in its approach. Instead, this 'first stage' of legal philosophical inquiry involves identifying, selecting and explaining law's important and significant features. Many of those features so identified and explained will be highly relevant to law's eventual moral evaluation and criticism, and many of them will be important and significant precisely because they are relevant to law's moral evaluation and criticism. For example, law's claim to possess moral authority, and the normative consequences of that claim, are important and significant features of law. They are important and significant precisely because they bear upon what matters to us regarding the effects law can have on our lives, and because they are acutely relevant to the judgements we must make concerning what attitude we ought to adopt towards law, how it ought to figure in our practical reason, and whether we ought morally to obey it, at all, and/or precisely in the way and for the reasons that law demands. ${ }^{58}$

According to IELP, then, there is no doubt that we must investigate law's moral properties, its connections with practical reason, its possible moral point or purpose, its legitimacy and authority etc., and that these are important tasks for legal philosophy. However, this approach claims that we must investigate such matters as part of a 'staged' inquiry, so that, at the outset of our investigations, our attitude should be that we will undertake moral evaluation and criticism of law, but not yet. Why not yet? To a significant extent, because of various points already mentioned in the discussion above: a fear of prematurely venerating law; a wariness of developing an unquestioning attitude towards it and being too-ready to comply with it; and an acute awareness of the potentially morally disastrous effects of such attitudes.

IELP thus contends that those of its critics who maintain that it is isolationist in character, and seeks to hermetically seal legal philosophy from the rest of political, social and moral philosophy, are sorely mistaken, and labour under a key misapprehension: that it is up for grabs whether legal philosophy is situated in the context of, continuous with, and fruitfully related to, inquiries in political, social, and moral philosophy. The reality is that none of this is in doubt, certainly not as regards my own views, and possibly not as regards anyone's views. The issue is not whether legal philosophy is part of, situated in the context of, and, in a certain sense, continuous with inquiries in political, social, and/or moral philosophy. The issues are: what is the exact character of the relations between these enterprises, and in what precise sense is legal philosophy part of, continuous with, and tied to them? These are matters deserving further exploration.

\section{CONCLUSION: OURS IS A BROAD CHURCH}

I have sought throughout this article to present, and indicate my support for, a 'broad church' view of legal philosophy. In the course of the discussion, I have cast doubt on certain divisive ways of carving up the disciplinary territory. In my view, and perhaps especially given the state of some current debates in legal philosophy, we must strive to understand a wide variety of theoretical approaches in a charitable light, and in ways which seek to lessen, rather than exacerbate, false oppositions between them. If we can do so,

\footnotetext{
${ }^{57}$ My planned monograph, Dickson (n 3) will include a chapter on the 'Value of Staged Inquiry'.

58 See also Dickson (n 18), chapters 2-4 and 7 on this point.
} 
we will improve our collective understanding of aspects of law, and of facets of jurisprudential inquiry. We will see more clearly the forms and types of complementarity which may exist within and between theories of law, whilst not ignoring but rather reaching a more nuanced understanding of that which genuinely remains in dispute. For legal philosophy is a broad church, and law is a complex, multi-faceted phenomenon, which stands in need of elucidation from a variety of angles. 